\title{
Review Articles
}

\section{Public Opinion}

Public Opinion 1935-1946. Prepared by Mildred Strunk under the editorial direction of Hadley Cantril. Princeton, New Jersey, Princeton University Press, I95I, 1250p. \$25.

Here is a new, basic work of reference for leaders of governmental and voluntary enterprises, historians, social scientists and other students of public affairs and social customs. The Office of Public Opinion Research under the editorial supervision of $\mathrm{Had}$ ley Cantril, its director, aided by a Rockefeller Foundation grant, has assembled in this I 200 page $\left(84^{\prime \prime} \times\right.$ I I $\left.4^{\prime \prime}\right)$ volume the reported results of the first I2 years of the Gallup, Roper and other polling activities. To be more precise, the book under review summarized the published reports, from 1935 through 1946, of those national surveys of opinion by means of interviewing cross section samples of populations conducted by reputable polling organizations in the United States, the British Commonwealth of $\mathrm{Na}$ tions and most of the European countries outside the Iron Curtain (Brazil is also represented, as well as parts of Czechoslovakia and Hungary before the Iron Curtain dropped completely).

The editors have made no claims to completeness. Local poll results, except for a few special instances, were excluded, as were the numerous surveys of opinion, preferences or tastes carried on as market research, almost none of which are available for publication. But the approximately 12,000 separate survey results contained in the volume probably come near to being 100 per cent of the nationwide opinion polls made and published during these 12 years.

The editors were soundly equipped by experience and training to select and evaluate the poll results for inclusion. In the planning of their undertaking they had the expert guidance of Julian Boyd, Princeton's librarian, and Datus Smith, editor of the Princeton University Press. The resulting organization, arrangement and presentation of the survey results are simple, sensible and admirably suited to reference use. Each survey report is organized under its major subject heading. The 300 or more major headings are arranged alphabetically to form the body of the text. Since many of the surveys cover more than one subject, secondary subjects are also identified by a very extensive use of cross references appearing in the table of contents. For all headings the Library of Congress subject headings have been employed.

The table of contents is 44 pages in length, follows the alphabetical arrangement of the text, and with its voluminous cross references to major headings serves the purposes of an index as well as an outline of contents. In only one respect does it fail to serve this double purpose: i.e., in its reference of all personal names to the major subject heading, Persons. This subject in the text includes 90 separate polls, many of which contain a dozen or more names. Thus whereas the analytical table of contents enables the reader to locate quickly all the surveys of opinion on any subject, whether it be thrift, poll tax, or football, the task of finding the polls which include the names of particular personalities such as Elmer Davis, Clare Boothe Luce or Babe Ruth, requires quite a few pages of thumbing. This, however, is a very minor defect in what otherwise is a logical, practical organization for ready use of a huge mass of material.

The editors indicate that the present volume will be the first of a series covering the survey results of successive five-year periods. Students of opinion may devoutly hope that the reception and widespread use of this first compilation will lead to its continuance. In the meantime there is now available for use during intervening years before publication of the periodic collections the section called "The Quarter's Polls" appearing in each issue of the Public Opinion Quarterly. This section is under the editorship of Mrs. Mildred Strunk who was in direct charge of the 1935-46 compilation; the same Library of Congress subject matter headings are used in both; and the form of presentation is identical. With the five-year compilations and these Public Opinion $Q$ uarterly reports of current surveys for 
each four-month's period, the student will have quick, convenient access to the published surveys of opinion on any subject from the beginning of systematic sample surveys of citizens down to the present. As the span of years lengthens during which surveys are reported, the historian or social analyst will have for his use an increasingly reliable index of the complexion, direction, ebb and flow of conscious, expressed opinion on public issues and social interests.

The reliability of the results of the polls themselves is a matter of continued, intensive study by experts in the field as well as by informed and uninformed critics from the outside. The editors of Public Opinion 19351946 do not discuss the methodology employed in the surveys they report, except to indicate the usual sample size employed by each of the polling organizations represented in the volume. For the rest, we are obliged to take on faith the zeal of the pollsters in perfecting their techniques for drawing representative samples of the population, in designing their questions and in their skill and objectivity in conducting their interviews. Whatever may be lacking in the techniques of the poll results reported, the volume contains, as the editors state, "more reliable data than is elsewhere available" for public opinion research. It is truly "an indispensable storehouse of information" on opinion. Every social science reference collection should include a copy.-Robert D. Leigh, Columbia University.

\section{Unusual Reference Manual}

General Reference Department Staff Manual. Prepared by Mary N. Barton and Ellen F. Watson. Baltimore, Md., Enoch Pratt Free Library, 1950, 230p. \$1.75.

A library's staff manual ordinarily makes rather dull reading for an outsider. Desirable as such a tool always is for the orientation of the new staff member in a particular library, and beneficial as may be the results of the necessarily careful reexamination (and often revision!), of procedures and routines that are called for in order to get them down in black and white, the ordinary manual of another library is likely to be riffled through casually and then filed and forgotten in the box marked:
"Manuals of other libraries-to be examined for ideas when making our own."

The present staff manual, however, can hardly be called an "ordinary" manual, and there seem to be reasons for supposing that it may not share the fate of those that are. Certainly no harm would result if parts of this document came to be considered as "required reading" for reference assistants in any library. It would be nice to think that in the preparation of reference manuals for other libraries this one will be less "examined for ideas," than deliberately "used as a model."

Its unusualness lies not primarily in its size, even though (to the best of this reviewer's knowledge) no other library has come near to equalling the more than 200 offsetprinted $\left(8 \frac{1}{2} " \times \mathrm{I}^{\prime \prime}\right)$ pages in a manual for the Reference Department alone. The more usual thing is to find the department's procedures and routines presented on a halfdozen pages in a manual, much smaller than this, covering the work of all departments.

Of much more importance than mere size is the careful thought that quite obviously has been given to this work during its dozen years of preparation-thought that has resulted in a manual not only admirably fulfilling its chief purpose of helpfulness within a single institution, but also one that has led to the inclusion of much material that will be of interest to reference workers anywhere. Some of the book, it is true, is concerned with such characteristically "staff manual" kinds of information as the fact that the revolving date stamp is kept in the drawer below the telephone. Still more of the manual necessarily describes procedures, arrangements, practices and rules which would apply is their entirety to no other library. But along with these things there are sections such as "Attitude toward the reader" ( $p$. 36-38), and the whole of Part VI "Reference work: Techniques and Procedures" (p.6386 ), which are not only so applicable to reference work in general, but also which are so well done that these parts alone might easily justify shelving this manual on the "Professional Shelf" of almost any reference department. Beyond this, it is possible that some of the nearly 40 clearly-reproduced "forms," and some of the well thought-out and fully described routines may suggest to 